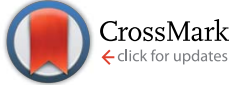

Cite this: J. Mater. Chem. A, 2016, 4, 3068

Received 22nd September 2015 Accepted 25th November 2015

DOI: $10.1039 / c 5 t a 07586 f$

www.rsc.org/MaterialsA

\section{Benchmarking nanoparticulate metal oxide electrocatalysts for the alkaline water oxidation reaction $\dagger$}

\author{
Suho Jung, ${ }^{\text {*a }}$ Charles C. L. McCrory, ${ }^{\text {*a }}$ Ivonne M. Ferrer, ${ }^{\text {ab }}$ Jonas C. Peters ${ }^{\star a b}$ \\ and Thomas F. Jaramillo*ac
}

Nanoparticulate metal-oxide catalysts are among the most prevalent systems for alkaline water oxidation. However, comparisons of the electrochemical performance of these materials have been challenging due to the different methods of attachment, catalyst loadings, and electrochemical test conditions reported in the literature. Herein, we have leveraged a conventional drop-casting method that allows for the successful adhesion of a wide range of nanoparticulate catalysts to glassy-carbon electrode surfaces. We have applied this adhesion method to prepare catalyst films from 16 crystalline metal-oxide nanoparticles with a constant loading of $0.8 \mathrm{mg} \mathrm{cm}^{-2}$, and evaluated the resulting nanoparticulate films for the oxygen evolution reaction under conditions relevant to an integrated solar fuels device. In general, the activities of the adhered nanoparticulate films are similar to those of thin-film catalysts prepared by electrodeposition or sputtering, achieving $10 \mathrm{~mA} \mathrm{~cm}{ }^{-2}$ current densities per geometric area at overpotentials of $\sim 0.35-0.5 \mathrm{~V}$.

\section{Introduction}

The storage of solar energy in the form of chemical bonds using integrated artificial photosynthetic devices comprised of earthabundant materials is a promising approach to generate clean and sustainable chemical fuels. ${ }^{\mathbf{1 1 4}}$ The development of such solar fuel devices requires the identification of efficient electrocatalysts for the water-splitting reactions. However, a lack of standardization in the measurement and reporting of watersplitting materials has made it difficult to compare the performance of electrocatalytic water-splitting systems under identical conditions. This lack of standardization in performance evaluation for electrocatalytic systems frustrates efforts to identify both the most promising catalysts for device integration and the technological gaps still to be overcome through the design of new materials and systems.

To establish a standardized protocol for catalyst measurement and reporting, we previously proposed a methodology for evaluating the activity and short-term stability of electrodeposited and sputtered electrocatalysts for the oxygen

\footnotetext{
ajoint Center for Artificial Photosynthesis, California Institute of Technology, Pasadena, CA, 91125, USA. E-mail: benchmarking@solarfuelshub.org

${ }^{b}$ Division of Chemistry and Chemical Engineering, California Institute of Technology, Pasadena, CA, 91125, USA

${ }^{c}$ Department of Chemical Engineering, Stanford University, Stanford, CA 94305, USA $\dagger$ Electronic supplementary information (ESI) available: Powder diffraction patterns; SEM images of drop-casted particles; electrical conductivity of metal oxides; activity and stability of metal oxides; Tafel plots; comparisons of OER activity for particulate films and other deposited films. See DOI: 10.1039/c5ta07586f
}

evolution reaction (OER) ${ }^{\mathbf{1 5}, 16}$ and the hydrogen evolution reaction (HER) ${ }^{\mathbf{1 5}}$ in aqueous alkaline and acidic solutions. As part of this benchmarking protocol, we identified a relevant primary figure of merit as the overpotential necessary to achieve $10 \mathrm{~mA}$ $\mathrm{cm}_{\text {geo }}{ }^{-2}$ (geometric area) current density, $\eta_{j=10 \mathrm{~mA} \mathrm{~cm}}{ }_{\text {geo }}{ }^{-2}$, the approximate current density expected in a $10 \%$ efficient integrated solar-to-fuels device under 1 sun illumination. ${ }^{11,17,18}$ Uniform application of this benchmarking methodology to dozens of HER and OER electrocatalytic films allowed us to identify several key trends in catalyst performance, but of particular interest is that most of the active OER catalysts showed similar activity in alkaline solution, achieving $10 \mathrm{~mA}$ $\mathrm{cm}_{\text {geo }}{ }^{-2}$ current densities at overpotentials of $\eta_{j=10 \mathrm{~mA} \mathrm{~cm}}{ }_{\text {geo }}{ }^{-2}=$ 0.35-0.6 V, ${ }^{15,16}$ lending support to the theorized existence of a minimum "thermodynamic overpotential" of $\sim 0.4 \mathrm{~V}$ for OER at planar metal-oxide surfaces. ${ }^{19,20}$

Nanoparticulate electrocatalysts for artificial photosynthetic devices are also of considerable interest because (i) their active surface areas can be controlled by controlling the nanoparticle size, suggesting that nanoparticles and other nanostructured materials may allow for very high surface area systems at relatively small catalyst loading per geometric area, ${ }^{21,22}$ (ii) they offer ease of control in synthesizing and characterizing material phases (composition and crystallinity) compared to deposited film syntheses, ${ }^{23}$ and (iii) the particle size and shape also may impact light scattering behavior in the solar-fuel devices. ${ }^{24}$ However, despite the numerous reports on particulate electrocatalysts for the OER, there is no standard method to evaluate particulate catalyst performances using consistent deposition methods and electrochemical test conditions. 
Table 1 Crystalline metal oxide OER catalysts investigated with surface area measurements

\begin{tabular}{llll}
\hline Oxide & Crystal structure & BET SA $\left(\mathrm{m}^{2} \mathrm{~g}^{-1}\right)$ & ECSA $\left(\mathrm{m}^{2} \mathrm{~g}^{-1}\right)$ \\
\hline $\mathrm{CoO}$ & Rock salt & $9.20 \pm 0.30$ & $0.25 \pm 0.17$ \\
$\mathrm{Co}_{3} \mathrm{O}_{4}$ & Spinel & $1.95 \pm 0.50$ & $0.19 \pm 0.03$ \\
$\mathrm{NiO}-(\mathrm{i})$ & Rock salt & $147.06 \pm 11.30$ & $0.65 \pm 0.23$ \\
$\mathrm{NiCoO}_{2}$ & Rock salt & $9.78 \pm 0.30$ & $0.49 \pm 0.20$ \\
$\mathrm{NiFe}_{2} \mathrm{O}_{4}$ & Spinel & $94.28 \pm 1.60$ & $0.14 \pm 0.04$ \\
$\mathrm{Fe}_{2} \mathrm{O}_{3}$ & Spinel & $34.10 \pm 1.20$ & $0.38 \pm 0.24$ \\
$\mathrm{IrO}_{2}-(\mathrm{i})$ & Rutile & $39.02 \pm 2.10$ & $52.98 \pm 3.04$ \\
$\mathrm{RuO}_{2}$ & Rutile & $11.38 \pm 0.10$ & $5.69 \pm 1.22$ \\
$\mathrm{LiCoO}_{2}$ & $\mathrm{ABO}_{2}$ layered & $0.28 \pm 0.01$ & $0.19 \pm 0.10$ \\
$\mathrm{LiNiO}_{2}$ & $\mathrm{ABO}_{2}$ layered & $1.53 \pm 0.01$ & $0.42 \pm 0.14$ \\
$\mathrm{LaCoO}_{3}$ & $\mathrm{ABO}$ perovskite & $1.27 \pm 0.10$ & $0.65 \pm 0.37$ \\
$\mathrm{LaNiO}_{3}$ & $\mathrm{ABO}_{3}$ perovskite & $3.96 \pm 0.30$ & $5.19 \pm 1.28$ \\
$\mathrm{Mn}_{2} \mathrm{O}_{3}$ & Scandium oxide & $3.28 \pm 0.10$ & $1.21 \pm 0.65$ \\
$\mathrm{MnO}$ & Rock salt & $1.54 \pm 0.10$ & $0.86 \pm 0.54$ \\
$\mathrm{MnO}_{2}$ & Rutile & $1.40 \pm 0.80$ & $0.50 \pm 0.03$ \\
$\mathrm{Mn}_{3} \mathrm{O}_{4}$ & Spinel & $1.02 \pm 0.50$ & $0.49 \pm 0.02$ \\
$\mathrm{Glassy}_{\text {carbon }}$ & N/A & N/A & N/A \\
& & &
\end{tabular}

Herein, we report a testing protocol for evaluating particulate electrocatalysts and use it to study a series of metal oxide nanoparticles for the OER under conditions relevant to an integrated solar-fuels device operating in alkaline solution.

Catalyst films are formed using a simple drop-cast method for the attachment of a wide range of particle catalysts onto glassy carbon working electrode substrates using a thin Nafion binder. ${ }^{25}$ This attachment strategy is conceptually similar to those previously reported for the immobilization of nanoparticulate electrocatalysts for the oxygen reduction reaction $(\mathrm{ORR})^{26-29}$ and the OER. ${ }^{25,30,31}$ Note that minimizing the thickness of the Nafion binder film is crucial to reduce oxygen transport resistance. ${ }^{29}$ We have applied this attachment method to study the OER performance of drop-casted electrocatalyst particles for 16 crystalline metal oxides (Table 1) selected due to their frequent use as OER electrocatalysts. The phase of the oxide materials are identified by X-ray powder diffraction, and images of the drop-casted particles are obtained by scanning electron microscopy (SEM). The surface areas of the metal oxide particles are estimated by two methods: (i) Brunauer-EmmettTeller (BET) gas adsorption of the catalyst particles, and (ii) electrochemically active surface area (ECSA) based on cyclic voltammetry measurements. Comparisons of the two surface area measurements are provided, and the appropriateness of each method for estimating electrocatalyst surface area is discussed. The activity and stability of each system is tested in alkaline solution ( $1 \mathrm{M} \mathrm{NaOH}$ ), and the performances of the oxide catalysts are compared.

\section{Experimental section}

\section{Materials}

All materials were used as received. The following nanoparticles used in this study were purchased from commercial vendors in specified grade: ruthenium(Iv) oxide $\left(\mathrm{RuO}_{2}, 99.9 \%\right)$, nickel(II) oxide (NiO-(i), nanopowder, $<50 \mathrm{~nm}$ particle size, 99.8\%), nickel(II) oxide (NiO-(ii), powder and chunks, 99.99\%), cobalt(II) oxide (CoO, $\geq 99.99 \%$ ), nickel(II) cobalt(II) oxide ((NiO)(CoO), nanopowder, $<150 \mathrm{~nm}, 99 \%)$, cobalt(II,III) oxide $\left(\mathrm{Co}_{3} \mathrm{O}_{4}\right.$, nanopowder, $<50 \mathrm{~nm}$ ), iron(III) oxide $\left(\mathrm{Fe}_{2} \mathrm{O}_{3},<5 \mu \mathrm{m}\right)$, lithium cobal$\mathrm{t}(\mathrm{III})$ oxide $\left(\mathrm{LiCoO}_{2}, 99.8 \%\right)$, lithium nickel(II) oxide $\left(\mathrm{LiNiO}_{2}\right.$, $\geq 98 \%$ ), manganese(II) oxide ( $\mathrm{MnO}, \geq 99.99 \%$ ), manganese(Iv) oxide $\left(\mathrm{MnO}_{2}, \geq 99.99 \%\right)$, manganese(III) oxide $\left(\mathrm{Mn}_{2} \mathrm{O}_{3}\right.$, $\geq 99.99 \%$ ), manganese(II,III) oxide $\left(\mathrm{Mn}_{3} \mathrm{O}_{4}, 97 \%\right.$ ), and iridium(IV) oxide $\left(\mathrm{IrO}_{2}\right.$-(ii), 99.9\%, >20 $\mu \mathrm{m}$ ) were purchased from Sigma Aldrich; iridium(II) oxide powder ( $\mathrm{IrO}_{2}-(\mathrm{i}), 20-32 \mathrm{~m}^{2} \mathrm{~g}^{-1}$ BET surface area according to the supplier) was purchased from Premetek; and nickel(II) iron(III) oxide $\left(\mathrm{NiFe}_{2} \mathrm{O}_{4}\right.$, nanopowder, 30 $\mathrm{nm}, 99.5 \%$ ) was purchased from MTI Corporation.

In addition, lanthanum(III) nitrate hexahydrate $\left(\mathrm{La}\left(\mathrm{NO}_{3}\right)_{3}\right.$ $\left.\cdot 6 \mathrm{H}_{2} \mathrm{O}, 99.999 \%\right)$, cobalt(II) nitrate hexahydrate $\left(\mathrm{Co}\left(\mathrm{NO}_{3}\right)_{2}\right.$ $\cdot 6 \mathrm{H}_{2} \mathrm{O}$, 99.999\%), nickel(II) nitrate hexahydrate $\left(\mathrm{Ni}\left(\mathrm{NO}_{3}\right)_{2} \cdot 6 \mathrm{H}_{2} \mathrm{O}, 99.999 \%\right)$, tetramethylammonium hydroxide pentahydrate (TMAH, $\left.\left(\mathrm{CH}_{3}\right)_{4} \mathrm{~N}(\mathrm{OH}) \cdot 5 \mathrm{H}_{2} \mathrm{O}, \geq 97 \%\right)$, nickel(II) nitrate hexahydrate $\left(\mathrm{Ni}\left(\mathrm{NO}_{3}\right)_{2} \cdot 6 \mathrm{H}_{2} \mathrm{O}, 99.999 \%\right)$, ammonium hydroxide $\left(\mathrm{NH}_{4} \mathrm{OH}\right.$, BioUltra), sodium hydroxide $(\mathrm{NaOH}$, BioUltra), sodium phosphate monobasic dihydrate $\left(\mathrm{NaH}_{2} \mathrm{PO}_{4}\right.$ $\cdot 2 \mathrm{H}_{2} \mathrm{O}$, BioUltra), and ammonium perchlorate $\left(\mathrm{NH}_{4} \mathrm{ClO}_{4}\right.$, 99.999\%) were purchased from Sigma Aldrich. Puratronic grade cobalt(II) sulfate heptahydrate $\left(\mathrm{CoSO}_{4} \cdot 7 \mathrm{H}_{2} \mathrm{O}, 99.999 \%\right)$ was purchased from Alfa-Aesar. 2-Propanol (ACS grade) was obtained from $\mathrm{BDH}$, and $5 \mathrm{wt} \%$ Nafion 117 solution in a mixture of lower aliphatic alcohols and water was purchased from SigmaAldrich. Oxygen cylinders $\left(\mathrm{O}_{2}\right.$, Alphagaz-1 grade 99.999\%) were purchased from Air Liquide. All water used was purified using a Thermo Scientific Barnstead Nanopure water purification system (18.2 $\mathrm{M} \Omega \mathrm{cm}$ resistivity).

\section{Perovskite oxide synthesis}

Lanthanum cobalt(III) oxide $\left(\mathrm{LaCoO}_{3}\right)$ and lanthanum nickel(III) oxide $\left(\mathrm{LaNiO}_{3}\right)$ were prepared by modifying literature methods. ${ }^{32-34}$ For both oxides, $0.2 \mathrm{M}$ of $\mathrm{La}\left(\mathrm{NO}_{3}\right)_{3} \cdot 6 \mathrm{H}_{2} \mathrm{O}$ and either $\mathrm{Co}\left(\mathrm{NO}_{3}\right)_{2} \cdot 6 \mathrm{H}_{2} \mathrm{O}$ or $\mathrm{Ni}\left(\mathrm{NO}_{3}\right)_{2} \cdot 6 \mathrm{H}_{2} \mathrm{O}$ were mixed with $1.2 \mathrm{M}$ TMAH to form a total of $250 \mathrm{~mL}$ solution. The mixtures were stirred overnight, and then washed with water at least 5 times using filter paper. The washed particles were then dried overnight in a gravity convection oven at $60{ }^{\circ} \mathrm{C}$. The dried powders were collected and ground using mortar and pestle. The resulting powders were then calcined on a ceramic boat in a 1 inch diameter quartz tube using a three-zone tube furnace (Mellen, SV Series Split furnace) in which all three zones were set to the same temperature as follows: $\mathrm{LaCoO}_{3}$ was calcined at $1000{ }^{\circ} \mathrm{C}$ for 5 hours in dry air with a flow rate of $\sim 9 \mathrm{slm}$ (standard liters per minute), and $\mathrm{LaNiO}_{3}$ was calcined in $\mathrm{O}_{2}$ at $800{ }^{\circ} \mathrm{C}$ for 5 hours in $\mathrm{O}_{2}$ at a flow rate of $\sim 9 \mathrm{slm}$. Finally the calcined powders were ground again using mortar and pestle.

\section{Analytical equipment}

Electrochemical measurements were conducted with a BioLogic VMP3 multichannel potentiostat/galvanostat with a builtin EIS analyzer. The working electrodes were $5 \mathrm{~mm}$ diameter 
disk electrodes with a surface area of $0.196 \mathrm{~cm}^{2}$, mounted into a Pine Instrument Company E6-series ChangeDisk RDE assembly and affixed to an MSR rotator. Reference electrodes were commercial saturated calomel electrodes (SCE) $(\mathrm{CH}$ Instruments) externally referenced to a solution of ferrocenecarboxylic acid (Sigma-Aldrich) in $0.2 \mathrm{M}$ phosphate buffer at $\mathrm{pH}$ $7(0.284 \mathrm{~V} v s \text {. SCE })^{35}$ prior to each set of experiments, and the auxiliary electrodes were carbon rods (99.999\%, Strem Chemicals). All data were recorded using the BioLogic EC-Lab software package (v.10.23).

The phases of the oxide materials were identified by powder $\mathrm{X}$-ray diffraction (XRD). A tabletop X-ray diffractometer (Bruker D2 Phaser) with $\mathrm{Cu}-\mathrm{K} \alpha$ as the radiation source was used to generate X-ray at the power of $30 \mathrm{kV} / 10 \mathrm{~mA}$. Peak matching was performed with Bruker DIFFRAC.EVA software. The BET (Brunauer-Emmett-Teller) surface areas of the oxide materials were estimated from nitrogen adsorption/desorption isotherms in powder forms using a surface area analyzer (Micromeritics Tristar II). The powder samples were de-gassed using a gentle flow of nitrogen at $150{ }^{\circ} \mathrm{C}$ for 5-10 hours, then immediately transferred to the sample tube for the measurements after weighing them.

The drop-casted nanoparticle images were obtained from scanning electron microscopy (SEM) using a Nova NanoSEM 450 FEI with a $15 \mathrm{kV}$ of accelerating voltage and a through-thelens detector (TLD). Some oxides required a stage bias of $\sim 400 \mathrm{~V}$ due to charging effects caused by low electrical conductivities.

\section{Working electrode preparation}

$5 \mathrm{~mm}$ diameter-glassy carbon disks (4 mm thick, Sigradur G, HTW Hochtemperatur-Werkstoff $\mathrm{GmbH}$ ) were used as working electrode substrates. The disks were lapped with silicon carbide abrasive papers (CarbiMet 2, 600/P1200, Buehler), followed by sequential polishing with diamond abrasive slurries (MetaDi Supreme, Buehler) in an order of $9 \mu \mathrm{m}, 6 \mu \mathrm{m}, 3 \mu \mathrm{m}, 1 \mu \mathrm{m}$, and $0.1 \mu \mathrm{m}$ diameter particle based slurries (1 min polishing each), to obtain mirror surfaces. Synthetic nap based polishing pads (MD Floc, Struers) were used for diamond polishing. The lapping and polishing were performed using a LaboSystem (LaboPol-5 and LaboForce-1, Struers) with 5 psi of applied pressure per disk, $8 \mathrm{rpm}$ of the head speed and $200 \mathrm{rpm}$ of the platen speed. To clean the polished disks, they were sonicated sequentially in pure water, acetone, and 2-propanol for 10 minutes each. The cleaned disks were then sonicated again in water for 10 minutes prior to use.

The dropcasting protocol reported here is modified from a literature protocol. ${ }^{25}$ Powder-based inks for each catalyst were made using $3.8 \mathrm{~mL}$ water, $1.0 \mathrm{~mL}$ 2-propanol, $40 \mu \mathrm{L}$ of $5 \%$ Nafion 117 solution, and $80 \mathrm{mg}$ of the oxide powder. Note that the powders used contained only the native oxide and were not supported on conductive media such as carbon black. The inks were sonicated for 10 minutes, and then $10 \mu \mathrm{L}$ of the inks were drop-casted onto mirror-polished glassy carbon disks using a micro-pipetter, followed by drying in an oven at $60{ }^{\circ} \mathrm{C}$ for 10 minutes.
Note that although the sulfonic acid sites in Nafion are very acidic, we do not believe the Nafion imparts significant catalyst degradation in the ink. This is because only a very small concentration of Nafion is used in the catalyst inks $(\sim 1.2 \mathrm{mg}$ $\left.\mathrm{L}^{-1}\right)$. Taking into account the equivalent weight of Nafion 117 ( $\sim 1100 \mathrm{~g}$ per sulfonic acid group), the resulting total concentration of acidic sites is $\sim 1 \mu \mathrm{M}$. This suggests the overall $\mathrm{pH}$ of the ink should be near neutral, and many of the Nafion sites will likely be deprotonated in the ink. $\mathrm{pH}$ measurements were conducted on several of the catalyst inks, and in general most had $\mathrm{pH} \geq 7$.

Electrodepositions of both nickel and cobalt onto glassy carbon electrodes were conducted in a $100 \mathrm{~mL}$ cell with $40 \mathrm{~mL}$ of an aqueous deposition solution. The metallic cobalt film was cathodically deposited onto a $5 \mathrm{~mm}$ diameter glassy carbon disk from a solution of $0.202 \mathrm{~g} \mathrm{CoSO}_{4} \cdot 7 \mathrm{H}_{2} \mathrm{O}$ and $0.164 \mathrm{~g} \mathrm{NH} \mathrm{NlO}_{4}$ ( $\mathrm{pH}$ adjusted to 6.8 with $\mathrm{NH}_{4} \mathrm{OH}$ ) at $-50 \mathrm{~mA} \mathrm{~cm}_{\text {geo }}{ }^{-2}$ for 30 seconds with the working electrode rotated at $200 \mathrm{rpm}$. The metallic nickel film was cathodically deposited in a solution of $1.047 \mathrm{~g} \mathrm{Ni}\left(\mathrm{NO}_{3}\right)_{2} \cdot 6 \mathrm{H}_{2} \mathrm{O}$ at $-16 \mathrm{~mA} \mathrm{~cm}_{\text {geo }}{ }^{-2}$ for 10 seconds with the working electrode rotated at $800 \mathrm{rpm}$. The carbon auxiliary electrode was separated from the glassy carbon working electrode and SCE reference electrodes using a fine-porosity glass frit (BioAnalytical systems, Inc.). $\mathrm{pH}$ measurements were conducted with a VWR Symphony multiparameter meter with a Thermo Scientific Orion refillable $\mathrm{Ag} / \mathrm{AgCl} \mathrm{pH}$ electrode filled with Orion $\mathrm{Ag} / \mathrm{AgCl}$ reference electrode filling solution.

In addition, metallic nickel, iridium, and ruthenium films were deposited onto glassy carbon disks via a reactive sputtering method based on a previously reported procedure. ${ }^{15,36}$ The glassy carbon disks were affixed to a glass slide using doublesided Kapton tape, and then the iridium and ruthenium were sputtered onto the electrode surface from an RF source at $200 \mathrm{~W}$ at $300{ }^{\circ} \mathrm{C}$ for $30 \mathrm{~min}$ under a constant flow of $3.0 / 3.0 \mathrm{sccm}$ (standard cubic centimeters per minute) $\mathrm{Ar} / \mathrm{O}_{2}$ for iridium, 4.5/ $0.5 \mathrm{sccm} \mathrm{Ar} / \mathrm{O}_{2}$ for ruthenium, using Ir and $\mathrm{Ru}$ targets, respectively ( $\geq 99.9 \%$ from AJA International). The nickel film was sputtered from an RF source at $150 \mathrm{~W}$ at room temperature under a constant flow of $20 \mathrm{sccm}$ Ar while maintaining an overall pressure of 8.5 mtorr for 35 min using a Ni target (99.95\%, ACI alloys).

\section{Electrochemical measurements}

The electrocatalyst-modified electrodes were mounted in the RDE assembly, and activity, stability, and surface area measurements were conducted in a 2-chamber U-cell as previously described. ${ }^{15,16}$ Briefly, the first chamber held the working and reference electrodes in $\sim 120 \mathrm{~mL}$ of $1 \mathrm{M} \mathrm{NaOH}$ solution, and the second chamber held the auxiliary electrode in $\sim 15 \mathrm{~mL}$ of 1 $\mathrm{M} \mathrm{NaOH}$ solution. Prior to each set of electrochemical tests, the electrolyte solution was bubbled with $\mathrm{O}_{2}$ for at least 30 minutes. During cyclic voltammetry (CV) measurements, the solution in the first chamber was blanketed under $\mathrm{O}_{2}$. During rotating disk electrode voltammetry (RDEV), chronoamperometry (CA), and chronopotentiometry (CP) measurements, the solution in the first chamber was continuously bubbled with $\mathrm{O}_{2}$. The 
uncompensated solution resistance $\left(R_{\mathrm{u}}\right)$ was measured with a high-frequency single-point impedance measurement at 100 $\mathrm{kHz}$ with a $20 \mathrm{mV}$ amplitude about the open-circuit potential (OCP), and RDEV and CA measurements were corrected for IR drop at $85 \%$ through positive feedback using the Bio-Logic ECLab software. CP measurements were manually corrected for IR drop. Our typical electrochemical setup resulted in $R_{\mathrm{u}}=\sim 10 \Omega$ in $1 \mathrm{M} \mathrm{NaOH}$.

Double layer capacitance was estimated in order to determine electrochemically active surface areas (ECSA) as previously described. ${ }^{15,16}$ In brief, a potential range in which there is minimal faradaic current response was estimated by CV. All measured current in this region is assumed to be a charging current due to double-layer charging. CV measurements were conducted in quiescent solution by sweeping the potential across this non-faradaic region from the more positive to negative potential and back at 8 different scan rates: 5, 10, 25, $50,100,200,400$, and $800 \mathrm{mV} \mathrm{s}^{-1}$. The working electrode was held at each potential vertex for $10 \mathrm{~s}$ before beginning the next sweep. ${ }^{15,16,37}$ Plotting the charging current as a function of the scan rate yields a straight line with the slope equal to the double-layer capacitance. The ECSA of the system is then calculated by dividing the double-layer capacitance by a general specific capacitance of $0.040 \mathrm{mF} \mathrm{cm}^{-2}$, a typical value reported for a metal electrode in an aqueous $\mathrm{NaOH}$ solution. ${ }^{\mathbf{1 6}}$

\section{Results and discussion}

\section{Materials characterization}

The phases of all the oxide materials were confirmed by powder diffraction patterns. As shown in Fig. S1-S6† and summarized

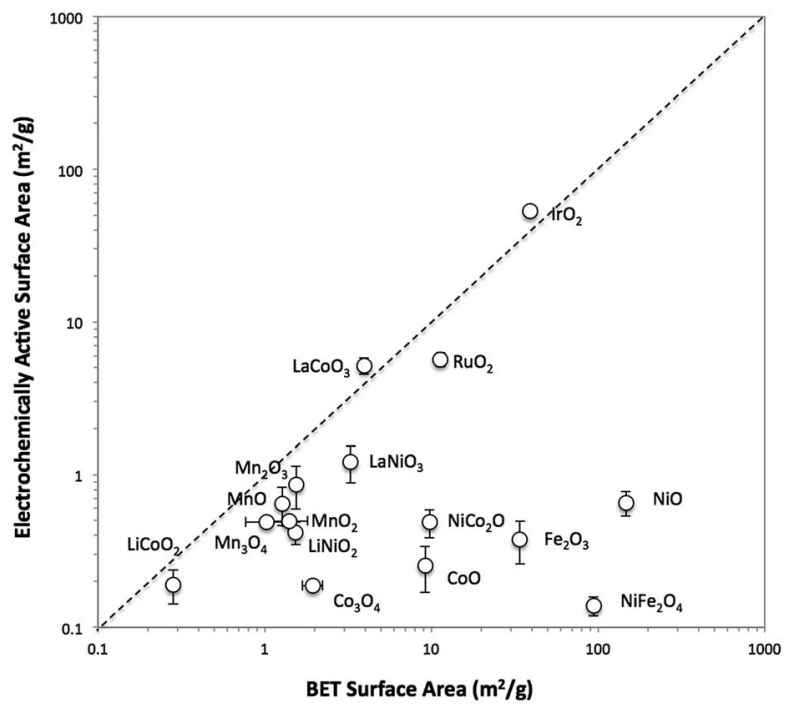

Fig. 1 The comparison of the BET surface area and the electrochemically active surface area (ECSA) by double layer capacitance for various metal oxides benchmarked in this study. The ECSAs were measured on immobilized particles on glassy carbon electrode surface prior to each activity measurement, and BET surface area was measured for samples in powder form. The iridium oxide and nickel oxide shown in this figure are $\mathrm{IrO}_{2}-(\mathrm{i})$ and $\mathrm{NiO}$-(i), respectively. in Table $\mathrm{S} 1, \dagger$ most of the oxide materials studied have rock salt, spinel, rutile, layered, and perovskite structures. The rock salt and spinel structures are primarily the oxides from the first-row transition metals that are based on the cubic system (CoO, NiO, and $\mathrm{NiCoO}_{2}$ for rock salt; and $\mathrm{Fe}_{2} \mathrm{O}_{3}, \mathrm{Co}_{3} \mathrm{O}_{4}$, and $\mathrm{NiFe}_{2} \mathrm{O}_{4}$ for spinel). Catalysts with the rutile structure, based on the tetragonal system, include the noble-metal oxides $\mathrm{IrO}_{2}$ and $\mathrm{RuO}_{2}$ which are known to have high activity for the OER with relatively high stability in aqueous solutions at various pH. ${ }^{10,11,15,38,39} \mathrm{LiNiO}_{2}$ and $\mathrm{LiCoO}_{2}$ are probably most well-known as lithium-ion battery cathode materials with a layered rhombohedral structure, although recently these layered $\mathrm{ABO}_{2}$ type oxides have been used for alkaline OER. ${ }^{\mathbf{4 0 - 4 3}}$ Lastly, $\mathrm{ABO}_{3}$-type perovskite-structured oxides, including $\mathrm{LaCoO}_{3}$ and $\mathrm{LaNiO}_{3}$, have been attracting increased interest due to their
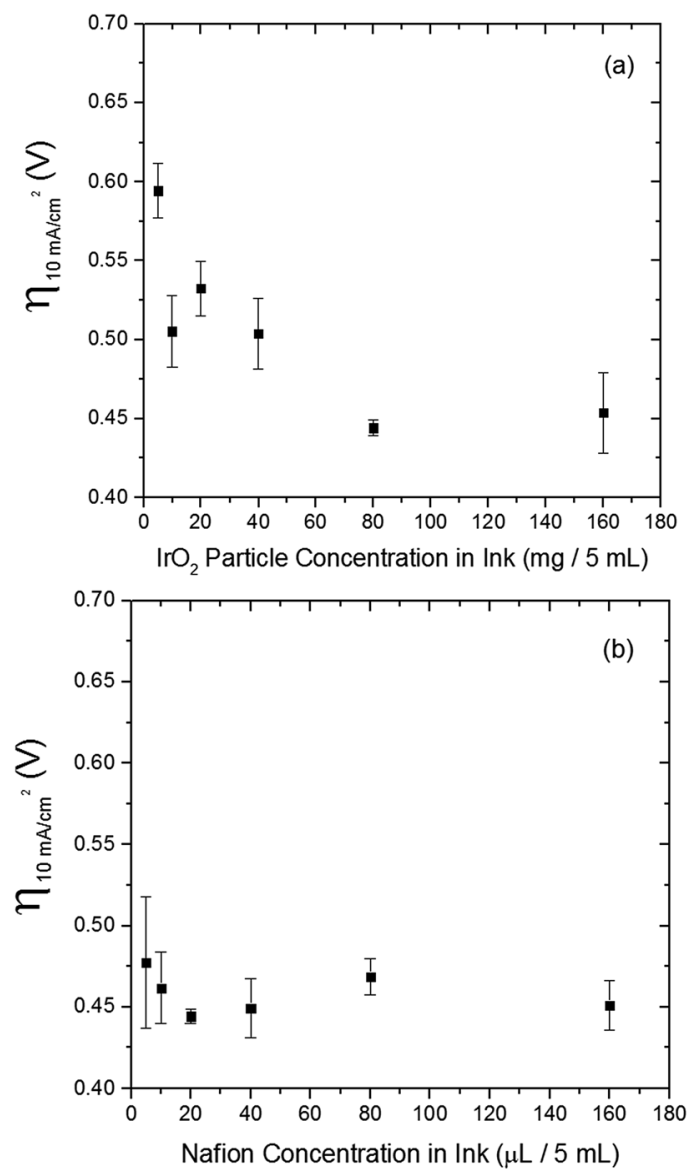

Fig. 2 The effects of $\mathrm{IrO}_{2}$-(i) particle and Nafion concentrations for the drop-cast on overpotential values at $10 \mathrm{~mA} \mathrm{~cm}_{\text {geo }}{ }^{-2}$ in $1 \mathrm{M} \mathrm{NaOH}$. (a) Effect of $\mathrm{IrO}_{2}$-(i) particle concentration on OER overpotential at a fixed Nafion concentration of $40 \mu \mathrm{L}$ in $5 \mathrm{~mL}$ solution. The overpotential value decreases as the iridium oxide loading increases, and then plateaus at around $80 \mathrm{mg} / 5 \mathrm{~mL}$. (b) Effect of Nafion concentration on OER overpotential at a fixed $\mathrm{IrO}_{2}$-(i) loading of $80 \mathrm{mg}$ in $5 \mathrm{~mL}$ solution. The Nafion concentration does not appear to influence the overpotential values significantly, but the overpotential shows relatively high variations in very small concentration ranges $(5-10 \mu \mathrm{L} / 5$ $\mathrm{mL}$ ), which can be attributed to catalyst adherence issues. The overpotential measurements were conducted with RDEV at $1600 \mathrm{rpm}$ and a scan rate of $10 \mathrm{mV} \mathrm{s}^{-1}$. 
Table 2 Relevant benchmark parameters for oxide OER catalysts in $1 \mathrm{M} \mathrm{NaOH}$

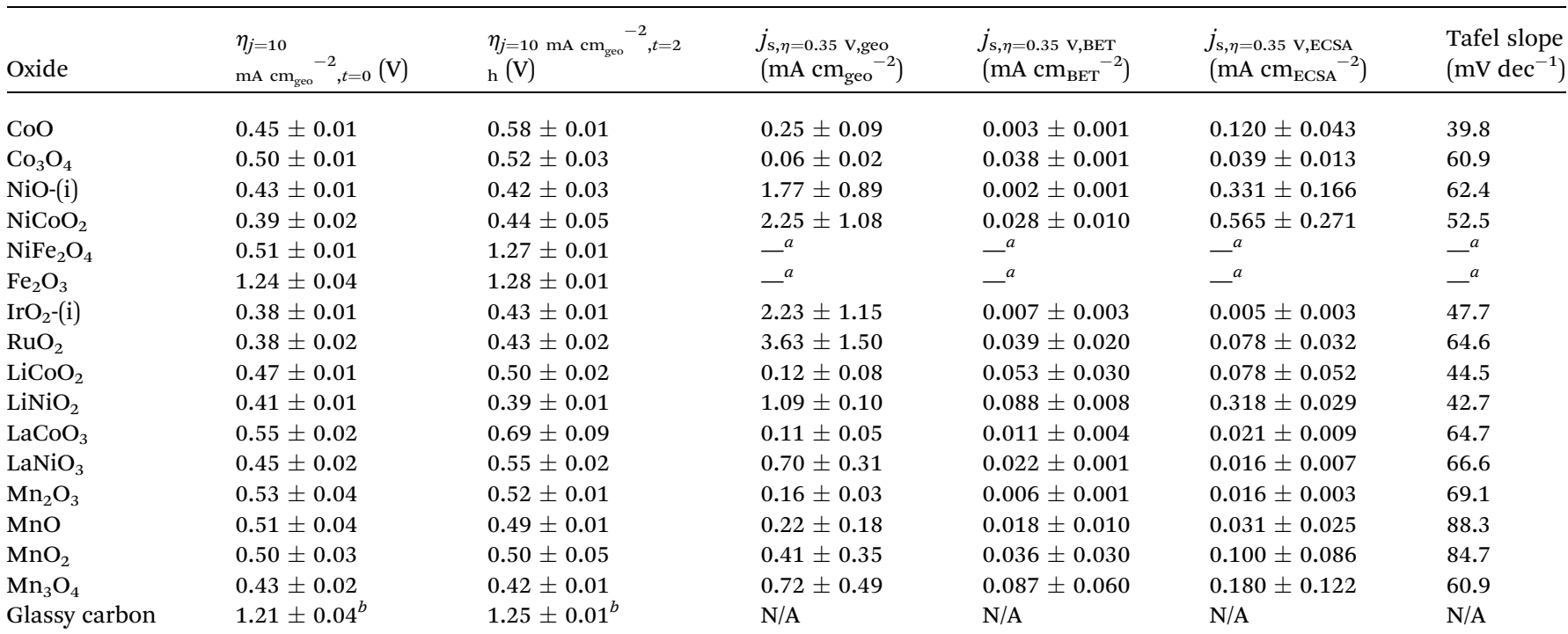

${ }^{a}$ The specific current densities and Tafel slopes of $\mathrm{Fe}_{2} \mathrm{O}_{3}$ and $\mathrm{NiFe}_{2} \mathrm{O}_{4}$ were not obtained, as they degraded during steady-state measurements. ${ }^{b}$ From ref. 16.

comparatively efficient OER activities, high electrical conductivities, and large composition spaces for doping $\mathrm{A}$ and $\mathrm{B}$ sites. $^{32,44-48}$ In addition to the above systems, four manganese oxides, all with different crystal structures, were also explored for this benchmarking study. Crystalline and amorphous Mnbased oxide materials have shown promise as bifunctional catalysts for the OER and ORR. ${ }^{18,49,50}$

The qualitative particle size and shape were examined by SEM, which are shown in Fig. S7-S12. $\dagger$ The images of the immobilized oxide particles overall do not show signs of thick Nafion film covering the particle layers. This suggests that the small amount of Nafion efficiently bind particles together and to the glassy carbon substrate without embedding the particles in a thick polymer film. The micrographs suggest that there is a wide range of particle size and shape when comparing the various nanopowders, ranging in size from $\sim 10 \mathrm{~nm}$ nanoparticles up to $10 \mu \mathrm{m}$ aggregates.

\section{Surface area measurements}

The surface area of each particle was characterized with two different methods, BET gas adsorption and ECSA. The BET surface area (BET SA) was measured ex situ using the raw powder form of the particle by evaluating nitrogen adsorption/desorption isotherms, whereas the ECSA was measured for the particle immobilized onto a glassy carbon disk in $1 \mathrm{M} \mathrm{NaOH}$. A direct comparison of the BET SA and ECSA of all 16 oxide particles is shown in Fig. 1. For convenience, ECSA has been converted from units of $\mathrm{cm}^{2}$ to units of $\mathrm{m}^{2} \mathrm{~g}^{-1}$ by dividing the ECSA area by the constant catalyst loading used in this study $\left(0.8 \mathrm{mg} \mathrm{cm}^{-2}\right)$. In general, the two methods of surface area determination do not give similar values. Most of the ECSA values are clustered in a narrow range between 0.1 and $1 \mathrm{~m}^{2} \mathrm{~g}^{-1}$, whereas BET SA values range from 0.1 to $1000 \mathrm{~m}^{2} \mathrm{~g}^{-1}$. Some exceptions include $\mathrm{IrO}_{2}$-(i),

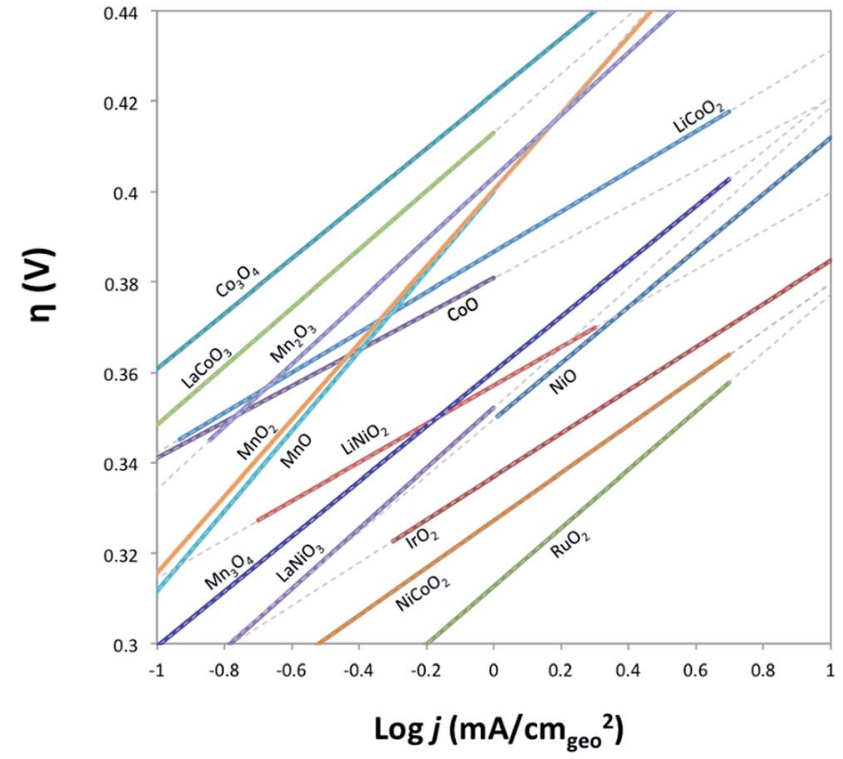

Fig. 3 Comparison of Tafel plots of various crystalline metal oxides in their linear regions. Solid lines indicate where the linear region of Tafel curve is obtained from, and the dashed lines show the extensions of the linear region. Raw Tafel curves are shown in Fig. S15-S21. $\dagger$ The iridium oxide and nickel oxide shown in this figure $\mathrm{are}_{\mathrm{IrO}}$-(i) and $\mathrm{NiO}$ (i), respectively. Tafel plots for $\mathrm{Fe}_{2} \mathrm{O}_{3}$ and $\mathrm{NiFe}_{2} \mathrm{O}_{4}$ oxides are not available as the oxides degrade on the timescale of the steady-state measurements used to generate the plots.

$\mathrm{RuO}_{2}, \mathrm{LaCoO}_{3}$, and $\mathrm{LaNiO}_{3}$ which show comparable BET SA and ECSA values greater than $1 \mathrm{~m}^{2} \mathrm{~g}^{-1}$.

To better probe the general discrepancy between the two methods, we compared the BET SA and ECSA of relatively high surface area, small particles of $\mathrm{IrO}_{2}$-(i) and $\mathrm{NiO}$-(i) to lowersurface area, large particles and aggregates of $\mathrm{IrO}_{2}$-(ii) and NiO- 
(ii). The phase of $\mathrm{IrO}_{2}$-(i) and NiO-(i) are equivalent to that of $\mathrm{IrO}_{2}$-(ii) and NiO-(ii), respectively, as measured by XRD, but the latter materials appear much coarser in SEM images as seen in Fig. S7 and S9. $\dagger$ The BET SA and ECSA of these four materials were measured and are compared in insets of Fig. S13. $\dagger$ The BET SA of the coarser $\mathrm{IrO}_{2}$-(ii) and NiO-(ii) particles are 8-20 times lower compared to those of the $\mathrm{IrO}_{2}$-(i) and NiO-(i) particles as expected. However, while a similar decrease in ECSA is observed when comparing $\mathrm{IrO}_{2}$-(ii) to $\mathrm{IrO}_{2}$-(i) particles, both the low-surface area NiO-(ii) and high-surface area NiO-(i) shows nearly equivalent ECSA values.

To test whether ECSA or BET SA is a better way of measuring the surface area relevant to catalysis for both $\mathrm{IrO}_{2}$ and $\mathrm{NiO}$ systems, the OER activity was measured using rotating disk electrode voltammetry (RDEV). The resulting voltammograms for the OER activity per geometric area $\left(\mathrm{mA} \mathrm{cm}_{\text {geo }}{ }^{-2}\right)$ for the two $\mathrm{NiO}$ and $\mathrm{IrO}_{2}$ systems are shown in Fig. S13. $\dagger$ In the case of $\mathrm{IrO}_{2}$, the activity per geometric areas of $\mathrm{IrO}_{2}$-(i) is significantly higher than that of $\mathrm{IrO}_{2}$-(ii). This is consistent with $\mathrm{IrO}_{2}$-(i) having a significantly higher surface area as suggested by both ECSA and BET measurements. In the case of NiO, the NiO-(i) activity is significantly higher than that of NiO-(ii), again suggesting that NiO-(i) has a higher catalytically-relevant surface area. This higher surface area for NiO-(i) is captured in the BET measurements, but is not evident from the ECSA measurements, suggesting that the BET area is a better descriptor of the catalytically-relevant surface area for NiO.

The inaccuracy of the ECSA measurements for NiO-(i) and NiO-(ii) may result from inaccurate measurements of double layer capacitance. In particular, we propose that more-insulating oxides such as $\mathrm{NiO}$ and $\mathrm{CoO}$ may provide additional capacitance during the ECSA measurements due to their dielectric behavior, a phenomenon not expected for moremetallic oxides such as $\mathrm{IrO}_{2}$ and $\mathrm{RuO}_{2} \cdot{ }^{38}$ This oxide capacitance for insulating oxides is likely small compared to the double layer capacitance, especially for high surface area systems. Because the small oxide capacitance and double layer capacitance are in series in the equivalent circuit, the overall capacitance measured from charging currents may more accurately reflect the smaller oxide capacitance as opposed to the larger double-layer capacitance.

A list of reported electrical conductivities for several of the oxides in this study is shown in Table S2. $\dagger$ We caution that the conductivities in the table were compiled from reports that use various sample types and do not necessarily reflect the actual conductivities of the materials under study here, but they still provide a qualitative guide that may be useful in establishing trends. For instance, metallic-like oxides with high conductivity such as the rutile oxides $\mathrm{IrO}_{2}$ and $\mathrm{RuO}_{2}$ and the perovskite oxides $\mathrm{LaNiO}_{3}$ and $\mathrm{LaCoO}_{3}$ all show similar BET SA and ECSA measurements. However, most of the other oxide particle studied show lower conductivities attributed to insulators and semiconductors. Most of these low-conductivity systems show similar ECSA $<1 \mathrm{~m}^{2} \mathrm{~g}^{-1}$ regardless of their BET surface area, suggesting that perhaps the capacitance measured for these systems is influenced or dominated by the oxide capacitance.
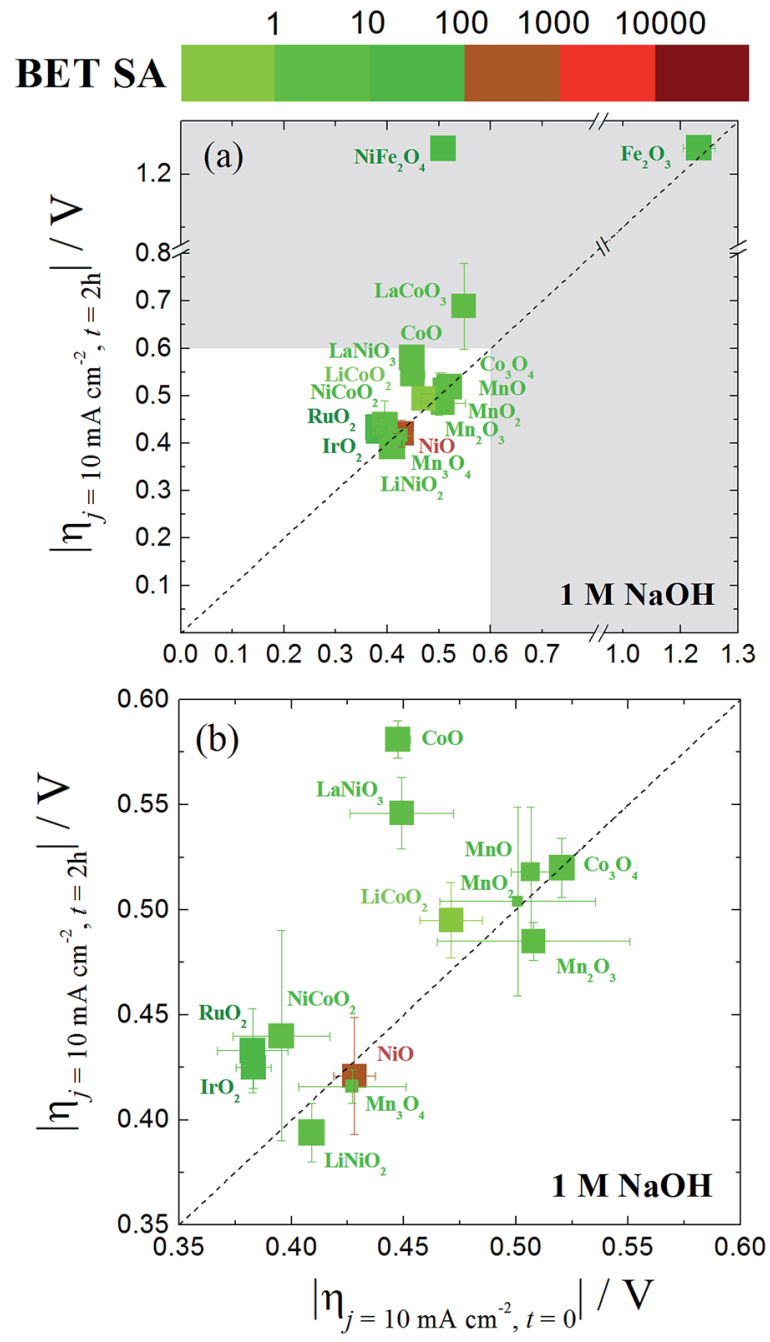

Fig. 4 (a) A comparative plot of catalyst activity, stability and BET surface area for nanoparticle OER electrocatalysts in $1 \mathrm{M} \mathrm{NaOH}$. The $x-$ axis is the overpotential required to achieve $10 \mathrm{~mA} \mathrm{~cm}_{\text {geo }}{ }^{-2}$ per geometric area at time $=0$. The $y$-axis is the overpotential required to achieve $10 \mathrm{~mA} \mathrm{~cm}_{\text {geo }}{ }^{-2}$ per geometric area at time $=2 \mathrm{~h}$. The dashed diagonal line indicates where the stable catalysts would lie on. The color of the each data point represents the BET surface area of the oxide catalyst with a bin size of one order of magnitude. Here the BET surface area is used because it provides an upper bound for the catalytically-active surface area. The size of each data point is inversely proportional to the standard deviation in the BET measurement reported in Table 1. The region of interest for benchmarking is the unshaded white region of the plot where the overpotential required to achieve $10 \mathrm{~mA} \mathrm{~cm}_{\text {geo }}{ }^{-2}$ per geometric area at time $=0$ and $t=2 \mathrm{~h}$ is less than 0.6 V. An inset of this area is expanded in (b). The iridium oxide and nickel oxide shown in this figure are $\mathrm{IrO}_{2}-(\mathrm{i})$ and $\mathrm{NiO}-(\mathrm{i})$, respectively.

Note that there are also several other factors that may be contributing to inaccuracy in the double layer capacitance determinations. In particular, pseudocapacitance due to surface coordination of ions and ion intercalation, chemical capacitance due to the population of trap states, and capacitance from any residual charge-transfer processes in the putative non-faradaic region may all also influence the measured capacitance, and therefore the estimated ECSA. 


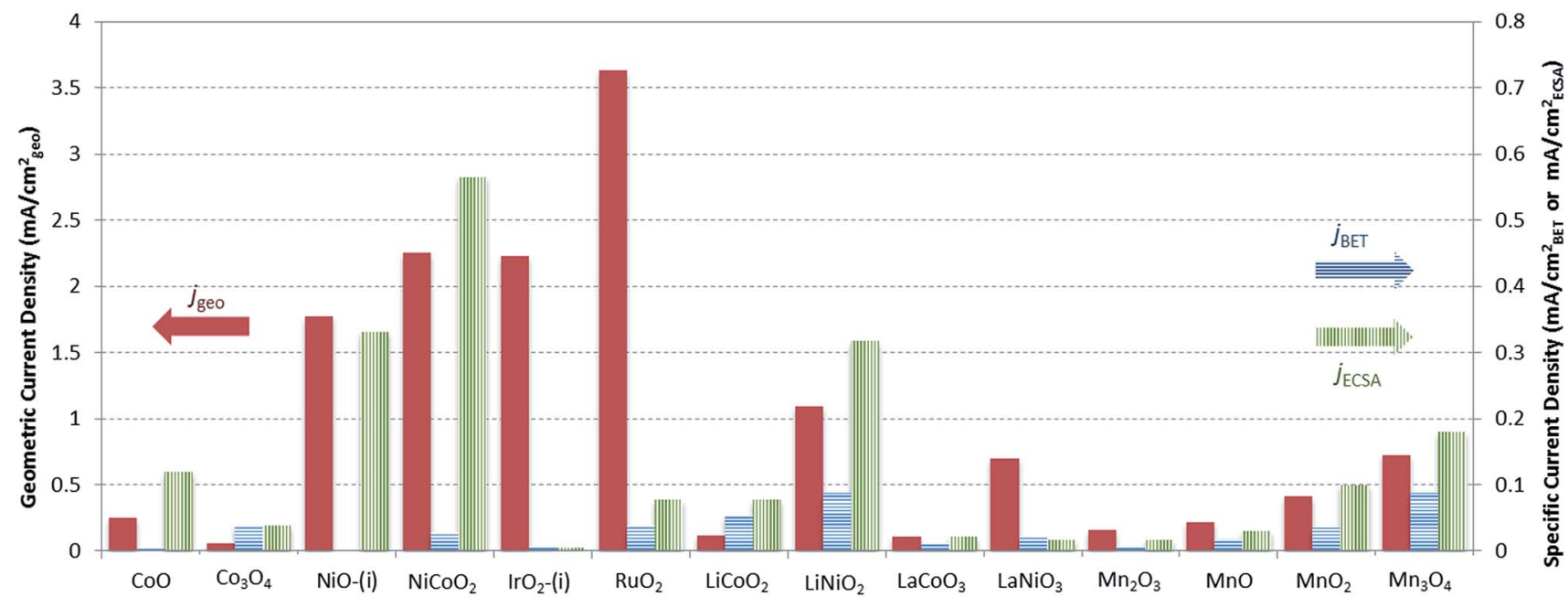

Fig. 5 The current density per geometric surface area (red), and specific current densities per BET surface area (blue) and ECSA (green) at $0.35 \mathrm{~V}$ overpotential in $1 \mathrm{M} \mathrm{NaOH}$. Due to the large difference between the measured geometric and specific current densities for most systems, two scales are used as shown in the figure, with the geometric current density plotted against the scale to the left, and the specific current density per BET and ECSA is plotted with the scale on the right.

These overall observations highlight the differences between ECSA and BET surface area measurements. In general, BET is a more well-defined empirical measurement that, in most cases, leads to an accurate description of the total surface area. However, the BET SA can potentially overestimate the catalytically-active surface area, as active sites are a subset of the total surface sites. Thus, normalization of activity data by BET SA leads to a conservative estimate of specific activity. By comparison, ECSA could in principle provide a more accurate description of the catalytically-active surface area. However, due to the difficulties in determining ECSA highlighted above, it may underestimate or overestimate the catalytically-active area. Ultimately, it is unclear whether ECSA or BET is more appropriate for estimating the catalytically-active surface area and depends greatly on the particular sample. Therefore, a recommended practice is to report both ECSA and BET SA so that the full range of possible surface areas and specific activities can be considered.

\section{Activity and stability measurements}

The electrocatalytic activity and short-term stability of each system was measured using a protocol we have previously described with the primary figure of merit being the overpotential necessary to achieve $10 \mathrm{~mA} \mathrm{~cm}_{\text {geo }}{ }^{-2}$ (geometric area). ${ }^{15}$ The choice of the loading of particles and Nafion binder used in this study is based on a loading optimization study for a stateof-the-art catalyst, $\mathrm{IrO}_{2}$-(i). Fig. 2 shows the activity of $\mathrm{IrO}_{2}$-(i) for the OER as a function of increasing concentrations of particles and Nafion in the drop-cast inks. The operating overpotential $\eta_{j=10 \mathrm{~mA} \mathrm{~cm}_{\text {geo }}{ }^{-2}}$ for particle films decreases with increasing particle concentration in the deposition inks for concentrations $<80 \mathrm{mg} / 5 \mathrm{~mL}$ ink, whereas the OER activity of $\mathrm{IrO}_{2}$-(i) drop-cast from solutions with concentrations of $80 \mathrm{mg} / 5 \mathrm{~mL}$ ink is identical to that at twice the loading of $160 \mathrm{mg} / 5 \mathrm{~mL}$ ink. The Nafion concentration of the deposition solution does not appear to appreciably influence the activity of the drop-casted $\mathrm{IrO}_{2}$-(i). Based on these measurements, an optimal particle concentration of $80 \mathrm{mg} \mathrm{mL} \mathrm{mL}^{-1}$ ink and Nafion concentration of $40 \mu \mathrm{L}$ Nafion/5 mL ink were identified for $\mathrm{IrO}_{2}$, which corresponds to a catalyst loading of $\sim 0.8 \mathrm{mg} \mathrm{cm}^{-2}$ in a $\sim 0.2 \mu \mathrm{m}$ thick Nafion film. This loading was then used for each catalyst film for consistency in the comparative activity measurements.

Representative RDEVs at $1600 \mathrm{rpm}$ and $2 \mathrm{~h}$ stability measurements for each catalyst investigated are shown in Fig. S14, $\dagger$ and their relevant activity and stability parameters are summarized in Table 2. Tafel plots for each system were constructed from the steady-state chronoamperometric and chronopotentiometric data at $1600 \mathrm{rpm}$, and representative curves for each catalyst are shown in Fig. S15-S21, $\dagger$ and the linear region of the Tafel plots for each catalyst are summarized in Fig. 3. Tafel slopes were determined from the curves in Fig. 3 and are also shown in Table 2. Although Tafel slopes are related to catalytic mechanism and materials with different Tafel slopes often operate with different mechanisms or rate-determining steps, they can be difficult to interpret for multi-electron reactions involving many possible intermediates with different rates of formation that may change with applied potential, such as the OER. ${ }^{11,51-53}$ Tafel slopes here are provided for comparison, but in-depth mechanistic analysis is beyond the scope and intent of this manuscript.

A graphical representation of the activity, stability, and surface area of each catalyst investigated is shown in Fig. 4. The advantage of this comparative plot is that it facilitates the comparison of activity, $2 \mathrm{~h}$ stability, and surface area for every catalyst investigated, and allows for the identification of trends in activity. As we have previously observed, ${ }^{15,16}$ the majority of the oxide materials examined here show similar activities, achieving $10 \mathrm{~mA} \mathrm{~cm}_{\text {geo }}{ }^{-2}$ current densities with overpotentials of $\eta=0.35-0.60 \mathrm{~V}$. It is also noted that this is somewhat 
expected since we purposely chose to investigate systems known to be electrocatalytically active for OER. In addition, to facilitate the comparison of the specific activity of each system, the geometric activity, specific activity per ECSA, and specific activity per BET SA are shown in Fig. 5.

Although many of the electrocatalysts investigated here have approximately similar activity, it is still possible to identify a few systems with promising comparative electrocatalytic performance. Of the catalysts investigated, $\mathrm{IrO}_{2}-(\mathrm{i}), \mathrm{RuO}_{2}$, and $\mathrm{NiCoO}_{2}$ showed the highest activity, achieving $10 \mathrm{~mA} \mathrm{~cm}_{\text {geo }}{ }^{-2}$ current densities at overpotentials of $\eta=0.38-0.39 \mathrm{~V}$. Of the three systems, note that $\mathrm{NiCoO}_{2}$ and $\mathrm{RuO}_{2}$ have significantly lower BET SA and ECSA than $\mathrm{IrO}_{2}$-(i) and therefore they show larger comparative specific current densities as shown in Fig. 5. Other particularly active catalyst include $\mathrm{LiNiO}_{2}, \mathrm{Mn}_{3} \mathrm{O}_{4}$, and $\mathrm{NiO}$, each showing promising activity and stability with operating overpotentials of $\eta_{t=0} \sim \eta_{t=2 \mathrm{~h}} \sim 0.42 \mathrm{~V}$. Note that $\mathrm{LiNiO}_{2}$ and $\mathrm{Mn}_{3} \mathrm{O}_{4}$ operate with higher specific current densities per BET SA of $90 \mu \mathrm{A} \mathrm{cm}_{\mathrm{BET}}{ }^{-2}$ at $0.35 \mathrm{~V}$ overpotential, compared to all other systems, suggesting that their inherent catalytic activities may be higher than the others.

\section{Conclusions}

The OER performance of 16 different crystalline metal oxides, all deposited with the same method and loading, were evaluated and compared under identical alkaline conditions relevant to an integrated artificial photosynthetic device under 1 sun illumination. The surface areas of the particulate materials were determined with both BET and ECSA methods, but there was not a strict correlation between the resulting surface areas measured with both methods. BET surface area measurements like provide an upper bound to the active surface area, providing a more conservative estimate of specific activity. However, it is unclear whether BET or ECSA is a more accurate estimate of the true active sites of the system. Because specific activity is often used to differentiate between catalyst activity of particulate systems, and because it is unclear whether BET or ECSA is a more accurate measurement for catalytically-active surface area, we suggest that both be reported for particulate electrocatalysts. Using both ECSA and BET surface areas provides a limiting range of specific activities that allows researchers to better compare the performance of particulate OER materials.

The activity and stability of each system were evaluated using a standard benchmarking protocol, ${ }^{15}$ and the activity, stability, and surface area of the catalysts were summarized in a graphical representation to facilitate the comparison of catalyst performance. In particular, all the OER materials investigated operate with similar activity, achieving $10 \mathrm{~mA} \mathrm{~cm}_{\text {geo }}{ }^{-2}$ current densities with overpotentials of $\eta=0.35-0.60 \mathrm{~V}$. Including this report and some of our previous studies, ${ }^{15,16,54}$ we have now shown that over 50 of the most well-known and/or active systems for the OER operate with similar activity when measured under identical conditions in alkaline solution.

Note that while all of the materials in this study operated within a narrow activity range owing to our choice of OER electrocatalysts known to be comparatively efficient, some materials did show better OER performance than their peers. In particular, $\mathrm{NiCoO}_{2}$ showed similar activity to that of $\mathrm{RuO}_{2}$ and $\mathrm{IrO}_{2}$ with an operating overpotential of $\eta=0.39 \mathrm{~V}$. Other systems of interest include $\mathrm{Mn}_{3} \mathrm{O}_{4}$ and $\mathrm{LiNiO}_{2}$. While these systems operated with slightly higher overpotentials than $\mathrm{RuO}_{2}$, $\mathrm{IrO}_{2}$, and $\mathrm{NiCoO}_{2}$ at $10 \mathrm{~mA} \mathrm{~cm}$ geo $^{-2}$ per geometric area, they achieved large current densities per BET SA of $j_{\mathrm{s}}=0.09 \mathrm{~mA}$ $\mathrm{cm}_{\mathrm{BET}}{ }^{-2}$ at $\eta=0.35 \mathrm{~V}$, nearly $2-3$ times that of any other catalyst investigated. This suggests that $\mathrm{Mn}_{3} \mathrm{O}_{4}$ and $\mathrm{LiNiO}_{2}$ are promising candidates for further studies to increase their surface area, and therefore their OER activity per geometric area, either by decreasing the catalyst particle size or through the formation of porous, nanostructured materials.

\section{Acknowledgements}

This material is based upon work performed by the Joint Center for Artificial Photosynthesis, a DOE Energy Innovation Hub, supported through the Office of Science of the U.S. Department of Energy under Award Number DE-SC0004993. We would like to acknowledge much assistance in BET measurements by Kurt M. Van Allsburg.

\section{Notes and references}

1 A. Fujishima and K. Honda, Nature, 1972, 238, 37-38.

2 M. Graetzel, Acc. Chem. Res., 1981, 14, 376-384.

3 A. J. Bard and M. A. Fox, Acc. Chem. Res., 1995, 28, 141-145.

4 O. Khaselev and J. A. Turner, Science, 1998, 280, 425-427.

5 N. S. Lewis and D. G. Nocera, Proc. Natl. Acad. Sci. U. S. A., 2006, 103, 15729-15735.

6 P. V. Kamat, J. Phys. Chem. C, 2007, 111, 2834-2860.

7 G. W. Crabtree and M. S. Dresselhaus, MRS Bull., 2008, 33, 421-428.

8 R. van de Krol, Y. Liang and J. Schoonman, J. Mater. Chem., 2008, 18, 2311-2320.

9 H. B. Gray, Nat. Chem., 2009, 1, 7.

10 T. R. Cook, D. K. Dogutan, S. Y. Reece, Y. Surendranath, T. S. Teets and D. G. Nocera, Chem. Rev., 2010, 110, 64746502.

11 M. G. Walter, E. L. Warren, J. R. McKone, S. W. Boettcher, Q. Mi, E. A. Santori and N. S. Lewis, Chem. Rev., 2010, 110, 6446-6473.

12 Y. Tachibana, L. Vayssieres and J. R. Durrant, Nat. Photonics, 2012, 6, 511-518.

13 F. E. Osterloh, Chem. Soc. Rev., 2013, 42, 2294-2320.

14 Z. Li, W. Luo, M. Zhang, J. Feng and Z. Zou, Energy Environ. Sci., 2013, 6, 347-370.

15 C. C. L. McCrory, S. Jung, I. M. Ferrer, S. M. Chatman, J. C. Peters and T. F. Jaramillo, J. Am. Chem. Soc., 2015, 137, 4347-4357.

16 C. C. L. McCrory, S. Jung, J. C. Peters and T. F. Jaramillo, J. Am. Chem. Soc., 2013, 135, 16977-16987.

17 M. F. Weber and M. J. Dignam, J. Electrochem. Soc., 1984, 131, 1258-1265. 
18 Y. Gorlin and T. F. Jaramillo, J. Am. Chem. Soc., 2010, 132, 13612-13614.

19 M. T. M. Koper, J. Electroanal. Chem., 2011, 660, 254-260.

20 I. C. Man, H.-Y. Su, F. Calle-Vallejo, H. A. Hansen, J. I. Martínez, N. G. Inoglu, J. Kitchin, T. F. Jaramillo, J. K. Nørskov and J. Rossmeisl, ChemCatChem, 2011, 3, 1159-1165.

21 A. J. Esswein, M. J. McMurdo, P. N. Ross, A. T. Bell and T. D. Tilley, J. Phys. Chem. C, 2009, 113, 15068-15072.

22 E. A. Paoli, F. Masini, R. Frydendal, D. Deiana, C. Schlaup, M. Malizia, T. W. Hansen, S. Horch, I. E. L. Stephens and I. Chorkendorff, Chem. Sci., 2015, 6, 190-196.

23 C. M. Sanchez-Sanchez, J. Solla-Gullon and V. Montiel, in Electrochemistry: Volume 11-Nanosystems Electrochemistry, The Royal Society of Chemistry, 2013, vol. 11, pp. 34-70.

24 J. McKone and N. Lewis, in Photoelectrochemical Water Splitting: Materials, Processes and Architectures, The Royal Society of Chemistry, 2013, pp. 52-82, DOI: 10.1039/ 9781849737739-00052.

25 T. Reier, M. Oezaslan and P. Strasser, ACS Catal., 2012, 2, 1765-1772.

26 F. Gloaguen, F. Andolfatto, R. Durand and P. Ozil, J. Appl. Electrochem., 1994, 24, 863-869.

27 U. A. Paulus, T. J. Schmidt, H. A. Gasteiger and R. J. Behm, J. Electroanal. Chem., 2001, 495, 134-145.

28 T. J. Schmidt, H. A. Gasteiger, G. D. Stäb, P. M. Urban, D. M. Kolb and R. J. Behm, J. Electrochem. Soc., 1998, 145, 2354-2358.

29 J. Suntivich, H. A. Gasteiger, N. Yabuuchi and Y. Shao-Horn, J. Electrochem. Soc., 2010, 157, B1263-B1268.

30 A. Grimaud, K. J. May, C. E. Carlton, Y.-L. Lee, M. Risch, W. T. Hong, J. Zhou and Y. Shao-Horn, Nat. Commun., 2013, 4, 2439.

31 X. Lu and C. Zhao, J. Mater. Chem. A, 2013, 1, 12053-12059.

32 J. O. M. Bockris and T. Otagawa, J. Electrochem. Soc., 1984, 131, 290-302.

33 B. Seyfi, M. Baghalha and H. Kazemian, Chem. Eng. J., 2009, 148, 306-311.

34 J. Suntivich, H. A. Gasteiger, N. Yabuuchi, H. Nakanishi, J. B. Goodenough and Y. Shao-Horn, Nat. Chem., 2011, 3, 546-550.
35 E. Liaudet, F. Battaglini and E. J. Calvo, J. Electroanal. Chem., 1990, 293, 55-68.

36 J. M. Spurgeon, J. M. Velazquez and M. T. McDowell, Phys. Chem. Chem. Phys., 2014, 16, 3623-3631.

37 J. D. Benck, B. A. Pinaud, Y. Gorlin and T. F. Jaramillo, PLoS One, 2014, 9, e107942.

38 Y. Matsumoto and E. Sato, Mater. Chem. Phys., 1986, 14, 397426.

39 S. Trasatti, Electrochim. Acta, 1984, 29, 1503-1512.

40 G. P. Gardner, Y. B. Go, D. M. Robinson, P. F. Smith, J. Hadermann, A. Abakumov, M. Greenblatt and G. C. Dismukes, Angew. Chem., Int. Ed., 2012, 51, 1616-1619.

41 S. W. Lee, C. Carlton, M. Risch, Y. Surendranath, S. Chen, S. Furutsuki, A. Yamada, D. G. Nocera and Y. Shao-Horn, J. Am. Chem. Soc., 2012, 134, 16959-16962.

42 N. Li, J. Li, L. Yang, H. Gao, S. Li and B. Lin, Electrochim. Acta, 2001, 46, 717-722.

43 T. Maiyalagan, K. R. Chemelewski and A. Manthiram, ACS Catal., 2014, 4, 421-425.

44 A. Costa, M. E. M. Jorge, M. D. Carvalho, A. Gomes and M. I. da Silva Pereira, J. Solid State Electrochem., 2013, 17, 2311-2318.

45 E. M. Garcia, H. A. Tarôco, T. Matencio, R. Z. Domingues and J. A. F. dos Santos, Int. J. Hydrogen Energy, 2012, 37, 64006406.

46 R. N. Singh and B. Lal, Int. J. Hydrogen Energy, 2002, 27, 4555.

47 J. Suntivich, K. J. May, H. A. Gasteiger, J. B. Goodenough and Y. Shao-Horn, Science, 2011, 334, 1383-1385.

48 A. Vojvodic and J. K. Nørskov, Science, 2011, 334, 1355-1356. 49 Y. Meng, W. Song, H. Huang, Z. Ren, S.-Y. Chen and S. L. Suib, J. Am. Chem. Soc., 2014, 136, 11452-11464.

50 H.-Y. Su, Y. Gorlin, I. C. Man, F. Calle-Vallejo, J. K. Norskov, T. F. Jaramillo and J. Rossmeisl, Phys. Chem. Chem. Phys., 2012, 14, 14010-14022.

51 A. J. Bard and L. R. Faulkner, Electrochemical Methods, Wiley, New York, 2nd edn, 2001.

52 J. O. M. Bockris, J. Chem. Phys., 1956, 24, 817-827.

53 J. O. Bockris and T. Otagawa, J. Phys. Chem., 1983, 87, 29602971.

54 S. Suseno, C. C. L. McCrory, R. Tran, S. Gul, J. Yano and T. Agapie, Chem.-Eur. J., 2015, 21, 13420-13430. 